of the apparent selection of source cases, contact tracing frequently was initiated in cases with minimal infectiousness or with MOTT. Whether this approach is unique to our facility or more widely practiced is unknown. We believe that the benefit of contact tracing can be increased by improving the source-case selection and the method of carrying out the investigation. Regarding case selection, two elements may have an impact on the effectiveness of the investigation: the likelihood of TB and the extent of infectiousness. The clinical and radiological characteristics, unfortunately, are nonspecific. ${ }^{5}$ A positive smear and preliminary culture results could not distinguish TB from infection with MOTT; gene probes were unavailable during this study period. Furthermore, the predictors of infectiousness (cavitary disease, positive smear, and forceful cough) are most valuable in confirmed TB. Therefore, we believe that, in facilities with a low-to-moderate rate of $\mathrm{TB}$, contact tracing should be limited to confirmed infectious TB and highly suspected cases, especially where transmission to household contacts is documented. Then, intensely exposed subjects should be screened first. Once transmission is documented, the investigation can be extended to others with less

TABLE

Relative Risk for Tuberculosis Exposure in Contact Tracings

\begin{tabular}{lrlll}
\hline & \multicolumn{3}{c}{ Investigation (N=21) } & Traced Days (N=115) \\
\cline { 2 - 4 } Risk of infection & \multicolumn{3}{c}{$\mathbf{N}(\%)$} \\
\hline None* $^{*}$ & 5 & 36 & $(31)$ \\
Low $^{\dagger}$ & 10 & $(48)$ & 56 & $(49)$ \\
Potentially high $^{\ddagger}$ & 6 & $(28)$ & 23 & $(20)$
\end{tabular}

* Mycobacterium other than tuberculosis.

† Smear-negative non-cavitary tuberculosis; smear-positive culture-negative tuberculosis on therapy; smear-positive culturenegative uncertain diagnosis.

₹ Untreated smear-and culture-positive for cavitary tuberculosis

intense exposure. This strategy likely will improve the outcome of the investigational approach and free resources for better utilization. We caution that this proposed strategy may not be appropriate without compliance to regularly scheduled skin testing and may not be applicable to facilities having a higher prevalence of TB, suboptimal engineering conditions, or HCWs with risk factors for disease progression.

\section{REFERENCES}

1. Griffith DE, Hardeman JL, Thang Y, Wallace RJ, Mazurek GH. Tuberculosis outbreak among health care workers in a community hospital. Am J Respir Crit Care Med $1995 ; 152: 808-811$.

2. McGowan JE Jr, Jarvis WR. Nosocomial transmission of Mycobacterium tuberculosis: role of health care workers in outbreak propagation. J Infect Dis 1995;172:1542-1549.

3. Centers for Disease Control and Prevention. Guidelines for preventing the transmission of Mycobacterium tuberculosis in health-care facilities. MMWR 1994; 43(RR-13):1-132.

4. Centers for Disease Control and Prevention. Essential components of a tuberculosis prevention and control program. Recommendations of the Advisory Council for the elimination of tuberculosis. MMWR 1995;44(RR-11):1-34.

5. Scott B, Schmid M, Nettleman MD. Early identification and isolation of inpatients at high risk for tuberculosis. Arch Intern Med $1994 ; 154: 326-330$.

Joseph Baran, Jr, MD
Hitpreet Sanghera, MD
Riad Khatib, MD
St John Hospital and Medical Center
Detroit, Michigan

\title{
Comparable Specificity of Commercial Tuberculin Reagents
}

\section{Gina Pugliese, RN, MS Martin S. Favero, PhD}

Villarino and coinvestigators from the CDC conducted a doubleblind trial to compare the reaction size and specificity of skin testing with Aplisol, Tubersol, and the standard purified protein derivative (PPD-S1). Between May 14, 1997, and October $28,1997,1,555$ persons at low risk of latent $\mathrm{TB}$ infection in six US cities received four tuberculin skin reagents at sites assigned at random. These included simultaneous skin tests with
Aplisol, Tubersol, PPD-S1 and either a second PPD-S1 or PPD-S2 (a proposed new standard).

Reaction size at each injection site was measured by two investigators blinded to type of reagent. Aplisol produced slightly larger reactions than Tubersol, but this difference did not significantly change skin-test interpretation. The mean $\pm \mathrm{SD}$ reaction sizes were $3.4 \pm 4.2 \mathrm{~mm}$ with Aplisol, $2.1 \pm 3.2 \mathrm{~mm}$ with Tubersol, and $2.5 \pm 3.6 \mathrm{~mm}$ with PPD-S1. Assuming that all participants were uninfected, and using a $10-\mathrm{mm}$ cutoff, the specificities of the tests were high: Aplisol, 98.2\%; Tubersol, 99.2\%; and PPD-S1, 98.9\%. Significant variability was not detected in interobserver, host, and lot-to-lot reagent comparisons.

The researchers concluded that, using a cutoff of at least $10 \mathrm{~mm}$, testing with three different PPD reagents resulted in similar numbers of uninfected persons being classified correctly.

FROM: Villarino ME, Burman W, Wang YC, Lundergan L, Catanzaro A, Bock $\mathrm{N}$, et al. Comparable specificity of 2 commercial tuberculin reagents in persons at low risk for tuberculous infection. JAMA 1999;281:169-171. 


\section{1st International Congress of the Asia Pacific Society of Infection Control (APSIC)}

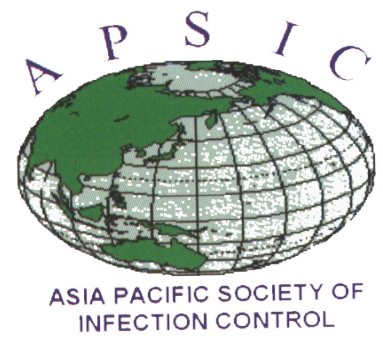

August 9-11, 1999, Main Congress in Hong Kong

August 8, 1999, Pre-Congress Workshop in Macau

$1^{\text {st }}$ International

第一屆亞太區感染控制會議

一九九九年八月九日至十一日，香港

一九九九年八月八曰，議會前工作坊，澳門

Congress

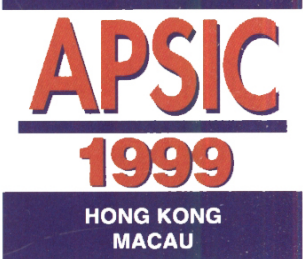

Infection Control in an Era of Change....

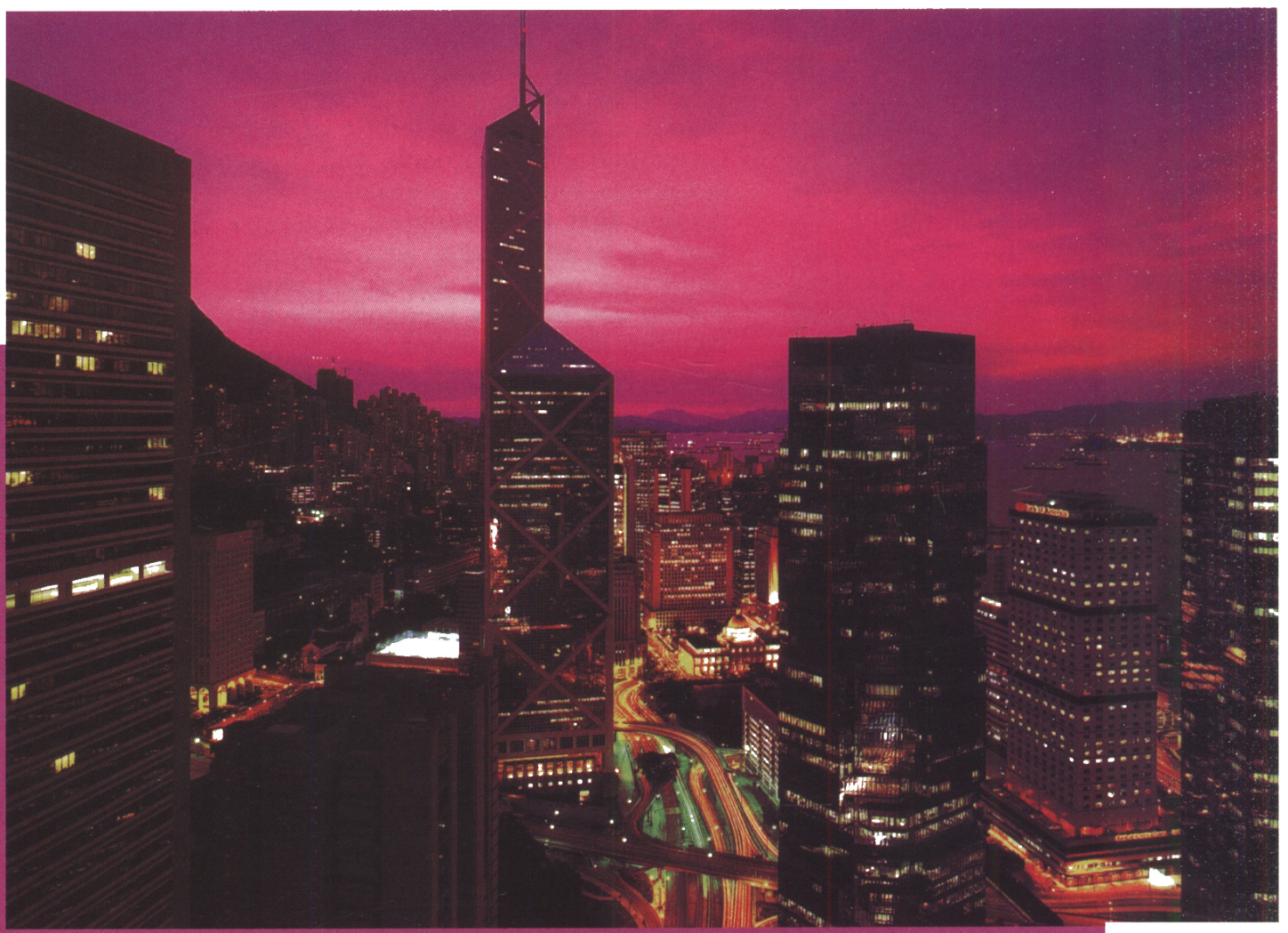

\section{Key Issues in the Congress:}

- Techniques and priorities in surveillance for Asia Pacific Infection Control.

- Hospital Waste - an update on Management and Technology.

- Currect Infection Control Issues in Pediatric Infections.

- Quality Standards and Local Realities in Central Supply.

- Update Perspectives on Sharps Management.

- Infection Control in Healthcare Workers.

- Minimizing the Risk for Endoscopes.

- Using CQI in Infection Control.

- What really works for control of gram+ve - MRSA, VRE, DRSP, VRSA etc.

- Emerging Pathogens and Asia Pacific Infectious Diseases.

- Infection Control issues in the Opeartive Suite

- Cost Saving in the Hospital and Infection Control.

- Reuse of Medical Devices.

\section{and Many More....}

